\title{
Español/castellano en Wikipedia: voces y foro de discusión
}

\section{Spanish/Castilian on Wikipedia: Voices and Discussion Forum}
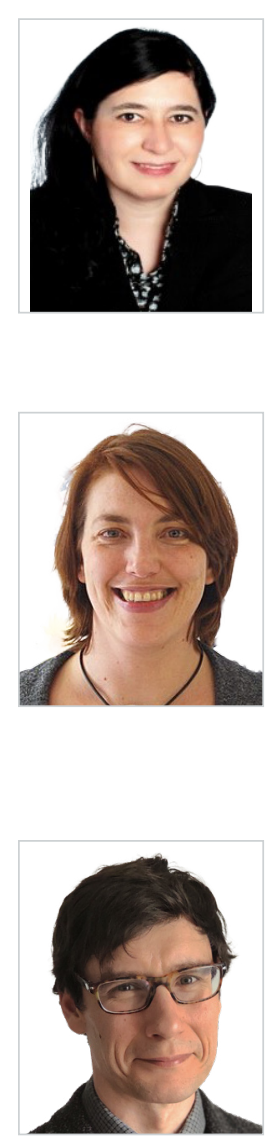

María Isabel Hernández Toribio. Profesora de la Universidad Complutense de Madrid, en el Departamento de Lengua Española y Teoría de la Literatura. Ha desarrollado su línea de investigación principalmente en el ámbito de la pragmática y el análisis del discurso. Entre sus publicaciones más recientes destacan algunas centradas en el análisis de tipologías de actos de habla en redes sociales como Twitter y en el discurso publicitario. Ha participado en diversos proyectos de investigación centrados en el análisis de los medios de comunicación y la publicidad. Ha impartido seminarios en numerosas instituciones universitarias. Ha sido visiting scholar en University of Southern California (Los Ángeles).

Universidad Complutense de Madrid, España

intor@ucm.es

ORCID: 0000-0002-1213-5610

Florencia Claes. Profesora ayudante doctora en la Universidad Rey Juan Carlos de Madrid donde imparte las asignaturas de Periodismo Multimedia y Comunicación Multimedia, en la Facultad de Comunicación. Logró los premios extraordinarios de licenciatura y doctorado en la Universidad Complutense de Madrid. Su campo de investigación son las redes sociales y las comunidades online, el posicionamiento SEO y el conocimiento libre centrado en el entorno Wikimedia. Ha publicado más de una decena de artículos de investigación sobre dichos temas y desde hace algunos años, lleva adelante diferentes talleres de formación en Conocimiento libre y Edición de Wikipedia para la Asociación Wikimedia España.

Universidad Rey Juan Carlos, Madrid, España

florencia.claes@urjc.es

ORCID: 0000-0003-4291-0507

Luis Deltell. Profesor titular en la Universidad Complutense de Madrid, imparte Dirección Cinematográfica en la Facultad de Ciencias de la Información. También ejerce de guionista y cineasta. Su campo de investigación es la historia de la imagen, el cine y el análisis de las nuevas tecnologías de las ciencias de la información y redes sociales. Ha publicado diversos artículos sobre Wikipedia y comunicación digital Codirige ESCINE, grupo complutense de estudio sobre cine. Ha sido visiting scholar en Stanford University y Berkeley University of California. Ha dirigido varios documentales y trabajos audiovisuales. El último de ellos es Un diálogo circunstancial (2019) codirigido con Isidoro Valcárcel Medina.

Universidad Complutense de Madrid, España

Ideltell@ucm.es

ORCID: 0000-0002-5230-1409

Cómo citar este artículo:

Hernández Toribio, M. I.; Claes, F. y Deltell, L. (2020). Español/castellano en Wikipedia: voces y foro de discusión. Doxa Comunicación, 31, pp. 283-302. 
Recibido: 20/07/2020 - Aceptado: 17/10/2020

\section{Resumen:}

En esta investigación hemos realizado un estudio, con metodología cuantitativa y cualitativa, de dos voces enciclopédicas y sus respectivas discusiones en la versión en español de Wikipedia. Los dos artículos monitorizados y analizados han sido "idioma español" y "controversia por el nombre del idioma español”, cuyo análisis nos ha permitido mostrar el modo de trabajo colaborativo de la enciclopedia online y el estudio de los foros de discusión que se generan en la construcción de estas entradas. Por ello, hemos analizado algunos aspectos de comportamiento propios de los foros virtuales y las estrategias de (des)cortesía más recurrentes en las discusiones que propicia la propia enciclopedia para su construcción. Los resultados muestran cómo Wikipedia en español es un entorno de trabajo que pretende seguir avanzando en la obtención de productos rigurosos y eficaces, arbitrando para ello una estructura endógena que actúe a modo de filtro/gestor de contenidos y formas de expresión. Hemos comprobado también cómo en la discusión sobre la construcción de estas voces se emplean estrategias de descortesía entre los usuarios y los editores, lo que denota una actitud que se desmarca de las normas de comportamiento de esta enciclopedia digital (los llamados “cinco pilares” de Wikipedia).

Palabras clave:

Wikipedia; Español; trabajo colaborativo; discusión; (des)cortesía.

\section{Introducción}

El impacto digital de Wikipedia desde su fundación hasta la actualidad ha sido extraordinario, propio de los llamados estudios de Big Data (Mayer-Schönberger y Cukier, 2013). Esta enciclopedia online cuenta con el mayor número de voces, pero, sobre todo, es la más consultada y la que tiene más actividad y número de colaboradores (Tramullas, 2015, Alexa, 2020). De hecho, durante el mes de marzo de 2020 se realizaron 25.322.788.228 visitas a alguna de las páginas del entorno Wikipedia (Wikistats, 2020).

Además, Wikipedia es un ejemplo paradigmático del trabajo colaborativo, de la denominada collective intelligence (Kubátová, 2012). Es precisamente dicho comportamiento colaborativo lo que intentamos demostrar en esta investigación a partir de un estudio de caso centrado en el análisis de dos artículos de la enciclopedia: "idioma español" y "controversia por el nombre del idioma español”. El análisis de estas voces enciclopédicas nos permitirá poner de manifiesto la política de edición de artículos de Wikipedia en la versión en español.

La primera versión de la enciclopedia online, en inglés, que presentaron Larry Sanger y Jimmy Wales el 15 de enero de 2001, tuvo como inspiración el proyecto Nupedia (Timothy, 2005), un ensayo previo y con alcance mucho menor al no estar basado en la creación colaborativa o wiki. A partir de entonces, el nacimiento y el crecimiento exponencial de otras versiones lingüísticas resultaron imparables. De hecho, la versión española se fundó unos meses después, el 20 de mayo 
del mismo año. La entrada "idioma español" que da paso al artículo correspondiente se generó -en la edición para hispanohablantes- el 15 de enero de 2002, es decir, un año después de la inauguración general de la enciclopedia, lo que pone de manifiesto el interés que, desde su creación, suscitó todo lo relacionado con la lengua (y sus variedades) que aúna a la comunidad de hispanohablantes.

Desde de la creación del artículo "idioma español” se generó un debate (discusión en los términos de Wikipedia) sobre todos los aspectos relacionados con esta lengua y sus variedades, entre ellos, las alternativas para su denominación: "español" versus "castellano". La discusión sobre la denominación del idioma fue tan intensa que desencadenó un segundo artículo titulado "controversia por el nombre del idioma español", hecho que pone de manifiesto que la construcción de la enciclopedia es un proyecto colaborativo de/para todas las comunidades hispanohablantes. Aunque la enciclopedia no es auspiciada por ninguna academia de la lengua ni institución (aspectos que están prohibidos por su propia política) y se construye con la colaboración desinteresada de los wikipedistas de cualquier región, Wikipedia en español ha adquirido tal relevancia que hasta el Instituto Cervantes le dedica un apartado en su informe anual sobre el estado del español en el mundo (Instituto Cervantes, 2019: 64).

En cualquier caso, al margen de estas cuestiones, nos interesa profundizar en el funcionamiento concreto de Wikipedia y, en especial, en el análisis pragmalingüístico de las controversias que sustentan la construcción de conocimiento en esta enciclopedia online en español. Controversias surgidas por la naturaleza del tema objeto de discusión. Análisis cuantitativos demuestran que, en las versiones de la enciclopedia de determinadas lenguas como el español (que abarca las variedades diatópicas españolas y americanas), las controversias generadas en torno a un artículo son fuertes por la descentralización de la enciclopedia. Según los datos del informe emitido por el Instituto Cervantes (2019: 5), "casi 483 millones de personas tienen el español como lengua materna. A su vez, el grupo de usuarios potenciales de español en el mundo (cifra que aglutina al Grupo de Dominio Nativo, el Grupo de Competencia Limitada y el Grupo de Aprendices de Lengua Extranjera) supera los 580 millones". Se trata de la segunda comunidad de hablantes nativos más importante de Wikipedia y, sobre todo, Wikipedia en español es una de las versiones que presenta una internacionalización mayor en la creación de contenidos. Desde hace una década se viene apreciando la descentralización de esta versión de la enciclopedia. En 2013 se constató que el 83,4\% del contenido de Wikipedia en alemán se construía desde Alemania; en la Wikipedia en francés, el 80,1\% del contenido se generaba desde Francia; en la italiana, un 95\% desde Italia... Por lo que respecta a la versión española, solo se generaba un 32,2\% desde España, un 14,1\% desde Argentina y un 12,6\% desde México; es decir, los tres países que más contribuían a la Wikipedia en español escribían solo el 58,9\% de sus contenidos (Wikistats, 2013) ${ }^{1}$. Por tanto, como se observa, se trata de una versión sin un polo -o estado- único de creación, lo que puede fundamentar la disparidad de criterios por las diferentes variedades diatópicas de los editores de contenidos, acicate, sin duda, para el surgimiento de controversias paralelas.

1 Aclaramos que estos datos están fechados en 2013 y que solo consideran ediciones de usuarios no registrados, es decir, desde IP. Aunque somos conscientes de la vaguedad de esta información, sí nos ayuda a confirmar que la creación en idioma español está claramente descentralizada con respecto a los otros idiomas. 
La descentralización a la que hacemos referencia puede apreciarse a partir del análisis de las dos voces objeto de estudio de este trabajo: “idioma español” y "controversia por el nombre del idioma español”. Las discusiones generadas entre los wikipedistas nos permiten ilustrar cómo se construye el conocimiento colaborativo en esta enciclopedia online. Además, vamos a analizar estrategias de (des)cortesía recurrentes en las discusiones generadas en torno a estos artículos. Como es conocido, todo artículo presenta una sección o espacio de "discusión" donde los usuarios/editores deben argumentar sus puntos de debate y así llegar al acuerdo necesario para la construcción de la voz. Aunque se indica explícitamente que no se trata de un foro para la polémica, su comportamiento es similar en muchos aspectos a los foros de debate de las redes sociales.

\section{Marco teórico}

\subsection{Caracterización de Wikipedia en español}

Si bien se define a Wikipedia como una enciclopedia, es, en realidad, la suma de 309 versiones lingüísticas -aunque una decena se encuentran en proceso de "incubación" por su baja actividad-. Cada una de estas ediciones es distinta y, aunque se construyan con el mismo objetivo de fiabilidad (Anexo: Wikipedias, 2020) y se rijan por las mismas normas, los "cinco pilares de Wikipedia" (2020), siguen comportamientos y hábitos de creación diferentes. Por lo tanto, es interesante remarcar que Wikipedia no se edita como una enciclopedia tradicional redactada en un idioma y posteriormente traducida a otros, sino que las 309 versiones son distintas (aunque puedan incluir traducciones o artículos similares). No existen versiones nacionales de Wikipedia, sino versiones lingüísticas (o en algún caso dialectales). Por ejemplo, Wikipedia en español es la edición común para todos los países hispanohablantes, y todos los usuarios de esta lengua y sus variantes, aunque residan en países no hispanohablantes, pueden no solo consultarla, sino también editarla -siempre que el sitio web esté disponible pues en algunas naciones como China no es legal (BBC, 2019)- . También, algunos países tienen enciclopedias online propias, pero están fuera de Wikipedia y son obras distintas: sirva de ejemplo que en Cuba existe EcuRed y en España, la Enciclopedia Libre Universal (Tkacz, 2011). Todas las versiones lingüísticas de Wikipedia se alojan dentro de un marco digital mayor llamado Wikimedia, en el que también se albergan otros proyectos hermanos, repositorios mundiales de fotografía, vídeos, recursos sonoros y digitales. Existe una enorme pluralidad de contenidos digitales (Wikimedia Foundation, 2020).

La Wikipedia en español es la novena versión idiomática en número total de voces incluidas, más de 1.600.000, pero la segunda del mundo por el número de usuarios, es decir, internautas que han realizado alguna actividad en el entorno digital en los últimos 30 días (List of Wikipedias by speakers per article 2018 y Wikistasts 2020). Esta evidente desproporción entre el número de voces y el número de usuarios parece indicar que la comunidad de hispanohablantes, aunque activa en sus consultas, es mucho más reticente a la creación de contenidos (Claes y Deltell, 2019).

En cualquier caso, a pesar de las divergencias referidas entre las diferentes versiones de la enciclopedia, existe en todas ellas una preocupación común por el mantenimiento del orden y la producción de un producto elaborado colectivamente en condiciones de descentralización; entendida como ausencia de ciertas estructuras jerárquicas y mecanismos 
centralizados de organización, de resolución de conflictos basados en la autoridad. No obstante, en su defecto, la política de Wikipedia deriva la resolución de las diferencias a los propios participantes. El orden surge de forma endógena en la red (Lerner and Lomi, 2020: 11). Durante el primer lustro desde su creación se debatió precisamente sobre la fiabilidad y rigurosidad de Wikipedia (Wedemeyer et al., 2008; Giles, 2005), reticencia que llega en muchos casos hasta la actualidad. No obstante, la bibliografía ha reconocido la calidad de algunas de las versiones más consolidadas, como la inglesa y la alemana (Hube, 2017).

\subsubsection{Estructura y funcionamiento de Wikipedia}

A pesar de la descentralización aludida, cada una de las versiones de Wikipedia intenta mantener un sistema organizativo similar, lo más adaptado posible a su idiosincrasia original, priorizando la mejora constante de los artículos y manteniendo siempre la base de la participación libre en la construcción de conocimiento colaborativo. Para analizar las estrategias de (des)cortesía (v. apartado 4.2.) que caracterizan las discusiones de esta enciclopedia online es conveniente tener en cuenta previamente los diferentes roles que desempeñan las personas que editan contenidos en Wikipedia, según su experiencia y sus conocimientos en torno a la misma. En líneas generales, las categorías existentes son:

A) Los editores, que son usuarios que generan contenido. Intervienen identificados -con un nombre de usuario o nickname- o de forma anónima -solo se les reconoce por su número IPs.

B) Si el usuario ha realizado una determinada cantidad de ediciones y lleva cierto tiempo de actividad, pasa a denominarse usuario autoconfirmado-que nunca pueden ser los editores IPs, categoría que los habilita para poder editar en artículos protegidos, es decir, aquellos que, ante reiterados "vandalismos", solo permiten ser editados por usuarios más avanzados. Los requisitos para ser usuario autoconfirmado varían según la lengua de la Wikipedia: por ejemplo, en español son necesarias más de 50 ediciones y un mínimo de 4 días de antigüedad (Autoconfirmados, 2020).

C) Los bibliotecarios son una categoría cuya jerarquía les permite realizar acciones superiores de administración y de control. En Wikipedia en español, según explica Patricio Lorente (2020: 82), están activos 70 bibliotecarios en todo el mundo, un número muy bajo para la cantidad de editores activos en español. Los bibliotecarios suelen intervenir para apaciguar conflictos, resolver problemas que exceden a las competencias de los editores y, sobre todo, llevan adelante tareas que otros usuarios no tienen habilitadas como la posibilidad de borrado o la protección de un artículo. Si un artículo es reiteradamente "vandalizado" -recibe ediciones malintencionadas o que violan reiteradamente las normas de edición-, pueden protegerlo o bloquear a los editores que llevan a cabo acciones en contra de la comunidad.

La interfaz wiki permite ver las contribuciones de todos los tipos de usuarios. Facilita la trazabilidad, es decir, el seguimiento y la construcción de los artículos. Los lectores o editores de Wikipedia pueden acceder a toda la información en el historial de edición: cómo se han construido los artículos, quiénes han participado en las tareas y la cantidad de visualizaciones. También se pueden consultar los contenidos que edita cada usuario (contribuciones de usuario) o los procesos de discusión para lograr un artículo consensuado (páginas de discusión).

Es importante destacar que Wikipedia posee una estructura interna que es menos conocida, pero que está disponible para cualquier internauta interesado: 
— Las páginas de usuarios: donde aquellos registrados pueden escribir sobre sus intereses y presentarse al resto de la comunidad.

- Las discusiones de usuarios: donde pueden dejar mensajes directos y públicos a otros usuarios. Funcionan de forma similar a las páginas de discusión de artículos y cualquiera puede intervenir en estos espacios.

- Café: zona de intercambio de ideas, propuestas y consultas en relación con el proyecto Wikipedia. Los usuarios pueden realizar peticiones sobre temas técnicos, ayuda a los más veteranos, proponer consultas comunitarias, etc.

Dentro de esta parte de la interfaz, accesible desde la portada, también se encuentra:

- El Tablón de anuncios de los bibliotecarios. Este espacio es una instancia superior en cuanto a resolución de problemas. Aquí se solicita ayuda a los administradores para dirimir conflictos de diferentes tipos. Los más usuales tratan de guerras de edición, avisos de mal comportamiento de algún usuario o sabotajes reitedados de un artículo, peticiones de restauración de artículos borrados, etc. Cuando el conflicto es tan grande que excede la posibilidad de resolverse en este espacio virtual, podría elevarse una petición a Meta Media Wiki como está ocurriendo en la actualidad con la Wikipedia en lengua croata, donde la mayoría de editores y bibliotecarios han conformado un núcleo de corte ultraderechista que expulsa del proyecto a todo editor que intente plantear un punto de vista alternativo a su forma de presentación de la información (Lorente, 2020: 81).

Aunque los estudios y la investigación sobre Wikipedia son ya frecuentes en otras lenguas, especialmente en inglés, en español suele existir cierta indefinición sobre los términos y conceptos básicos. No obstante, consideramos interesante hacer referencia a estos para mostrar que, aun en ausencia de centralización de la enciclopedia, esta jerarquiza cada vez más su forma de trabajo y arbitra los mecanismos (a modo de filtros) necesarios para la elaboración de contenidos, regida siempre por el ideal de adquirir rigor y fiabilidad. Por ello, proponemos un glosario sintético, a modo de resumen, de los elementos y sujetos básicos de la enciclopedia online en español (tabla 1).

Tabla 1. Vocabulario habitual entre los editores de Wikipedia y su definición

\begin{tabular}{|l|l|}
\hline Denominación & Definición \\
\hline $\begin{array}{l}\text { Usuario anónimo o usuario IP } \\
\text { (Unregistered: IP or not logged in) }\end{array}$ & $\begin{array}{l}\text { Persona que edita Wikipedia sin estar registrado con nombre de usuario. Habitualmente se los } \\
\text { denomina editores IP. }\end{array}$ \\
\hline $\begin{array}{l}\text { Usuario o editor } \\
\text { (Registered user) }\end{array}$ & Persona que se registra con nombre de usuario (nickname) y edita en la plataforma. \\
\hline $\begin{array}{l}\text { Usuario autoconfirmado } \\
\text { (Autoconfirmed) }\end{array}$ & $\begin{array}{l}\text { Editor con más de } 50 \text { ediciones y, al menos, } 4 \text { días de antigüedad. Puede editar algunos artículos } \\
\text { protegidos. }\end{array}$ \\
\hline $\begin{array}{l}\text { Verificador } \\
\text { (Reviewers) }\end{array}$ & Editor que solicita a la comunidad tener la posibilidad de dar por válidos artículos nuevos. \\
\hline $\begin{array}{l}\text { Bibliotecario } \\
\text { (Administrator) }\end{array}$ & $\begin{array}{l}\text { Editor que tiene la confianza de la comunidad para proteger artículos, borrarlos, restaurarlos, } \\
\text { bloquear usuarios con mal comportamiento y otras tareas no permitidas a usuarios. }\end{array}$ \\
\hline
\end{tabular}




\begin{tabular}{|c|c|}
\hline $\begin{array}{l}\text { Vigilante } \\
\text { (Watchers) }\end{array}$ & $\begin{array}{l}\text { Cualquier editor que seleccione -para su seguimiento- un artículo o página en Wikipedia. Cada } \\
\text { vez que esa página tenga una modificación, por ínfima que sea, le llegará un aviso de esa acción. } \\
\text { Suelen ser vigilantes de un artículo los editores que han invertido tiempo en la creación o mejora } \\
\text { de la voz, o personas interesadas en controlar cambios. }\end{array}$ \\
\hline $\begin{array}{l}\text { Bloqueo } \\
\text { (Blocking) }\end{array}$ & $\begin{array}{l}\text { Acción de no permitir a un usuario que siga editando. Puede darse sobre un artículo, en concreto, } \\
\text { o sobre la enciclopedia, en general. Puede ser temporal o definitivo. }\end{array}$ \\
\hline $\begin{array}{l}\text { Guerra de edición } \\
\text { (Edit wars) }\end{array}$ & $\begin{array}{l}\text { Cuando un editor escribe y/o deshace la edición de otro y viceversa, de forma sistemática, sin } \\
\text { respetar las políticas y convenciones de Wikipedia. Puede haber o no argumentación en la página } \\
\text { de discusión y se recurre al tablón de bibliotecarios para resolverla. }\end{array}$ \\
\hline $\begin{array}{l}\text { Tablón de bibliotecarios } \\
\text { (Requests for administrator } \\
\text { attention) }\end{array}$ & Zona habilitada para peticiones a los administradores/bibliotecarios de la enciclopedia. \\
\hline $\begin{array}{l}\text { Café } \\
\text { (Village pump) }\end{array}$ & $\begin{array}{l}\text { Espacio de discusión general abierto al intercambio de ideas, información, consultas, temas téc- } \\
\text { nicos, votaciones, propuestas de mejora de la comunidad, etc. Está ordenado por temas de inte- } \\
\text { rés. }\end{array}$ \\
\hline $\begin{array}{l}\text { Políticas y convenciones } \\
\text { (Policies and guidelines) }\end{array}$ & $\begin{array}{l}\text { Reglas de participación en Wikipedia, que se conforman por votación de la comunidad. Toman } \\
\text { como base "Los cinco pilares" y tratan temas como "El punto de vista neutral", qué implicaría } \\
\text { ignorar las normas, el civismo, políticas de borrado, etc. }\end{array}$ \\
\hline $\begin{array}{l}\text { Edición } \\
\text { (Edit) }\end{array}$ & Acción de modificar cualquier contenido en Wikipedia. \\
\hline $\begin{array}{l}\text { Deshacer } \\
(\text { Undo) }\end{array}$ & $\begin{array}{l}\text { Deshacer la edición de otro usuario (volver un paso atrás). Esta acción es muy sencilla, puesto que } \\
\text { las wikis facilitan el botón "deshacer" la edición en el historial de cualquier artículo. Es muy útil } \\
\text { ante comportamientos indeseados y un arma peligrosa en guerras de edición. }\end{array}$ \\
\hline $\begin{array}{l}\text { Artículo } \\
(\text { Article })\end{array}$ & Entorno principal donde están el contenido y la definición de la voz. \\
\hline $\begin{array}{l}\text { Página de discusión del artículo } \\
\text { (Talk page) }\end{array}$ & $\begin{array}{l}\text { Entorno asociado a un artículo donde los editores buscan un consenso sobre el contenido que se } \\
\text { desea mostrar en la zona principal del mismo. Es un espacio para el debate argumentado, cuyo } \\
\text { objetivo es la mejora del contenido de un artículo. }\end{array}$ \\
\hline $\begin{array}{l}\text { Artículo semi protegido } \\
\text { (Protected) }\end{array}$ & $\begin{array}{l}\text { Un artículo que solo puede ser editado por usuarios autoconfirmados, por tratarse de un tema } \\
\text { que suscita conflictos o vandalismos recurrentes. La protección la puede pedir cualquiera y la } \\
\text { aplica un bibliotecario. Si el conflicto es mayor, se puede proteger de forma total, de manera que } \\
\text { solo los bibliotecarios puedan editarlos. }\end{array}$ \\
\hline $\begin{array}{l}\text { Página de usuario } \\
\text { (User page) }\end{array}$ & $\begin{array}{l}\text { Página donde los editores pueden presentarse a la comunidad por intereses, aficiones, gustos de } \\
\text { edición. No está bien visto dar información personal. }\end{array}$ \\
\hline $\begin{array}{l}\text { Página de discusión de usuario } \\
\text { (User talk page) }\end{array}$ & $\begin{array}{l}\text { Lugar asociado a la página de usuario donde los editores pueden dejar mensajes al usuario en } \\
\text { cuestión. }\end{array}$ \\
\hline
\end{tabular}

Fuente: elaboración propia a partir de Wikipedia 


\subsection{Discusión o foro de debate}

La estructura de la enciclopedia, referida en la Tabla 1 (apartado 2.1.), pone de manifiesto que la discusión o foro de debate se convierte en un pilar básico entre las diferentes instancias enunciativas (usuarios, editores, administradores, bibliotecarios) para la construcción de Wikipedia. Por ello, entre los mencionados "cinco pilares" en los que se sustenta la política de Wikipedia, se encuentra el que hace referencia a la manera de llevar a cabo estas discusiones: la búsqueda de un "punto de vista neutral" (Los cinco pilares, 2020) que permita ofrecer información lo menos sesgada posible, teniendo en cuenta diferentes puntos de vista y sin que primen las meras opiniones personales. Explícitamente se señala que no se debe "presentar un punto de vista como el verdadero o el mejor". Sin embargo, esto resulta difícil de conseguir en las discusiones (Páginas de discusión, 2020), especialmente en las voces con más debate o controversia. Algo que, de hecho, algunos usuarios recriminan a otros:

(1) Hola Usuario: 186.56.197.62. Wikipedia no está para mostrar las cosas como alguien cree que deberían ser, sino para contar lo que las referencias dicen que son. Si tú piensas que "castellano" es anticuado, conservador o castellanista, eso no tiene importancia para el artículo, porque no se basa en tus opiniones ni en las mías [...] Saludos. Lin linao idime? 14:24 8 mar 2016 (UTC) (Discusión: idioma español, 2020).

Wikipedia es una enciclopedia abierta, configurada por la participación de usuarios que crean artículos, pero también un entorno para discutir sobre estas voces enciclopédicas e incluso, si fuera preciso, modificarlas, rechazarlas y retirarlas.

En este sentido, el (des)acuerdo forma parte de la dinámica instaurada en estas denominadas "discusiones", cuya finalidad es "la comunicación entre usuarios del proyecto con el objetivo de abordar asuntos relacionados con cualquier tema sobre la enciclopedia". Aunque la política de la página insiste en no categorizar las discusiones como espacios sociales y, sobre todo, como foros de opinión, no siempre se logra esta buena práxis. Por ello, es relativamente frecuente encontrar opiniones personales y valoraciones sesgadas.

En la enciclopedia online se insiste precisamente en diferenciar estas discusiones de los foros de discusión, es decir, "espacios donde se invita a los lectores a discutir o compartir información” (Pano Alamán, 2008: 29).

(2) Hola. Wikipedia no es un foro. Las páginas de discusión no están para opinar acerca del tema ("yo creo que está bien el arte". "Julio César no debería haber confiado en Bruto"), sino para tratar sobre los cambios que hacen falta en un artículo ("esta referencia puede servir para el arte rupestre", "hay unas faltas de ortografía en el nombre romano de Bruto"). Por eso, tu opinión sobre el nombre del idioma es adecuada para otro tipo de sitios, ya que en esta página nos ocupamos de lo que hay ahora: “español” o “castellano”. Saludos. Lin linao ¿̇dime? 00:44:15 ago 2016 (UTC) (Discusión: idioma español, 2020).

De hecho, aunque en Wikipedia no se recomienda mantener conversaciones personales prolongadas, sí se permite cierto grado de conversación particular. Por ello, parece que se intentan desvincular de aquellos foros de opinión en los que "el opinante no está, en principio, condicionado por un tópico particular y su texto, normalmente, «sube» sin muchos filtros a la red una vez enviado" (Vigara Tauste y Hernández Toribio, 2011: 355). Las discusiones de Wikipedia se intentan aproximar más bien -sin éxito, en ocasiones- a aquellos foros que se activan con un propósito-tema, que cuentan con un gestor (filtrador) de contenidos y de formas de expresión; es decir, a esos foros que se comportan como páginas "web para leer, escribir o comentar mensajes sobre un tema determinado" (Cassany, 2012: 210). Se intenta aprovechar el carácter de los 
foros de discusión asíncronos especializados, en los que se pretende que se realicen aportaciones reflexivas que permitan potenciar la habilidad del pensamiento crítico (Eligio Mendoza y otros, 2016: 100). Pero, al igual que en estos, tienen cabida la hostilidad, la divergencia, la competición entre los editores de los artículos. En las discusiones de Wikipedia sucede lo mismo que en los foros de debate, en los que "se asiste a menudo a un fenómeno de orden discursivo que se relaciona más bien con el intercambio polémico que con la búsqueda de un compromiso (Gouti, 2006)” (Pano Alamán, 2008: 35).

En cualquier caso, queda patente el alto nivel de conflicto existente en las discusiones de los artículos, llegando incluso a las que se han denominado edit wars ('guerras de edición'). Como veremos, la edición española no está exenta de esta problemática. Aunque se usa el término "colaboración", puesto que mucha gente está colectivamente participando en la producción de conocimiento, parece que no se trata solo de colaborar, sino de competir; de hecho, muchas intervenciones se limitan a modificar o retirar la aportación de otro autor (Collier y Bear, 2012: 385). Como correlato de esta situación, en este contexto, la defensa enconada de un punto de vista propicia la aparición de diversas estrategias de (des)cortesía.

\section{Metodología, objetivos y corpus de análisis}

En esta investigación llevamos a cabo un estudio cuantitativo y cualitativo de dos artículos y sus correspondientes discusiones en Wikipedia en español: "idioma español” y "controversia por el nombre del idioma español”. Abordamos el modo de construcción colaborativa en la enciclopedia online así como el análisis de los foros de discusión que se generan en la misma.

Objetivos

Ob.1. Monitorizar la actividad de las voces “idioma español” y “controversia por el nombre del idioma español”, y de sus respectivas discusiones.

Ob.2. Contabilizar el modo de creación de los artículos y discusiones: según el tamaño en número de bytes, caracteres y palabras; las visitas en los últimos 60 días, el número de ediciones y el número de editores (identificados, anóminos o IPs y bots).

Ob.3. Detallar la actividad de creación y vigilancia de las voces: según el número de vigilantes, el número de editores y el volumen de creación de los diez usuarios más activos. Investigar si se trata de un discurso monopolístico de "autoridad libre" (Claes y Deltell, 2020).

Ob.4. Analizar la pretendida calidad de las entradas, medida en función de algunos parámetros como las referencias: referencias unívocas, referencias científicas y académicas, así como el cuidado de las voces según el número de secciones y otros recursos.

Ob.5. Analizar cualitativamente las estrategias de (des)cortesía en las discusiones de los artículos objeto de estudio.

En nuestra investigación planteamos tres hipótesis de trabajo.

H.1. Que las voces “idioma español” y “controversia por el nombre del idioma español” en Wikipedia trasladan al entorno digital la complejidad y la pluralidad de este idioma, así como los propios debates en torno al mismo. 
H.2. Que las "discusiones" de ambas voces se presentan a modo de foros de debate amplios y plurales.

H.3. Que la construcción deWikipedia en español se realiza desde el consenso y sin que haya un dominio monopolístico.

\section{Discusión}

\subsection{Resultados y análisis de datos de las voces y sus discusiones}

Los resultados de la monitorización nos indican que las dos voces estudiadas tienen un importante volumen de actividad y de construcción (Tabla 2). Aunque, como parece lógico, es la voz “idioma español” la que presenta más participación e impacto dentro de la comunidad online. Para entender el impacto de "idioma español" es interesante indicar que este artículo se cita, o se hace referencia al mismo, en 47.951 voces distintas de la propia Wikipedia, algo que refleja hasta qué punto es esencial dentro de esta versión lingüística de la enciclopedia.

El primer dato significativo es el tamaño de los artículos: el de controversia tiene 3.060 palabras (en caracteres, 20.586) mientras que el del idioma, 10.322 (en caracteres, 67.949). La voz del idioma sería tres veces mayor. Es interesante analizar los bytes del artículo: el del idioma tiene 245.476 y la controversia solo 36.694. Como se observa, la voz del idioma es siete veces mayor; esto se debe a que usa más recursos visuales e imágenes que el otro artículo. La voz "idioma español" utiliza diversos planos para mostrar la expansión de esta lengua por el mundo y se recurre a fotografías e imágenes de las banderas nacionales para indicar los estados donde se habla este idioma. Lógicamente, todos estos recursos suponen un considerable aumento de bytes.

Sin embargo, en el aspecto que más destaca la voz "idioma español" es, sin lugar a dudas, en los índices de la pretendida calidad, ya que contiene un elevado número de referencias en la construcción del texto (con 520 en total), de las cuales el 76\% son unívocas (395); también sobresale por presentar una altísima cifra de vigilantes (546). Se trata, por tanto, de una voz controlada y estudiada por una auténtica comunidad. Más de medio millar de usuarios están atentos y reciben alertas automáticas ante cualquier modificación o cambio. Por ello, las actividades inadecuadas parecen poco probables en la construcción de esta voz. El artículo "controversia por el nombre del idioma español" es también importante en su número de vigilantes (90), pero muy inferior en el número de referencias: tan solo tiene 34 citas frente a las 520 de "idioma español".

Es cierto, como indican Rodríguez-Mateos y Hernández-Pérez (2018), que el número de referencias es importante, pero también lo es la calidad de las mismas, de hecho, las citas a revistas científicas actualizadas parecen más rigurosas que aquellas que se hacen a prensa generalista o a blogs no científicos. En el caso del artículo “idioma español”, la procedencia de las referencias es dispar. Aunque mayoritariamente son de organismos oficiales como fundaciones, academias de la lengua o constituciones nacionales, también hay ejemplos de prensa generalista. 
Tabla 2: información sobre editores y tamaño de las voces analizadas

\begin{tabular}{|c|c|c|c|c|}
\hline \multicolumn{5}{|l|}{ Nombre de la voz } \\
\hline & $\begin{array}{c}\text { Controversia por el } \\
\text { nombre del idioma } \\
\text { español }\end{array}$ & $\begin{array}{l}\text { Discusión del } \\
\text { artículo }\end{array}$ & Idioma español & $\begin{array}{l}\text { Discusión del } \\
\text { artículo }\end{array}$ \\
\hline \multicolumn{5}{|l|}{ Tamaño y características } \\
\hline Fecha de creación & $1 / 3 / 07$ & $2 / 3 / 07$ & $15 / 1 / 02$ & $21 / 9 / 03$ \\
\hline $\begin{array}{l}\text { Cantidad de lenguas en que se } \\
\text { encuentra el artículo }\end{array}$ & 7 & no corresponde & 268 & no corresponde \\
\hline Cantidad de palabras en el artículo & 3.060 & 4.759 & 10.322 & 27.349 \\
\hline Cantidad de caracteres & 20.586 & 28.910 & 67.949 & 169.205 \\
\hline Tamaño en bytes & 36.694 & 48.700 & 245.476 & 441.707 \\
\hline Secciones del artículo & 18 & 25 & 54 & 154 \\
\hline Enlaces entrantes & 9 & 2 & 47.951 & 44 \\
\hline Referencias & 34 & no corresponde & 520 & no corresponde \\
\hline Referencias unívocas & 32 & no corresponde & 395 & no corresponde \\
\hline \% referencias unívocas & $94 \%$ & no corresponde & $76 \%$ & no corresponde \\
\hline \multicolumn{5}{|l|}{ Editores } \\
\hline Total de editores por artículo & 338 & 104 & 3.612 & 596 \\
\hline $\begin{array}{l}\text {-editores identificados con nombre } \\
\text { de usuario }\end{array}$ & 139 & 57 & 1.156 & 290 \\
\hline -editores sin identificar (IPs) & 174 & 43 & 2.357 & 289 \\
\hline -editores bots & 25 & 4 & 99 & 17 \\
\hline \multicolumn{5}{|l|}{ Ediciones } \\
\hline $\begin{array}{l}\text { Promedio de ediciones por editor } \\
\text { (general) }\end{array}$ & 1,94 & 2,06 & 3,44 & 3,25 \\
\hline Promedio de ediciones por bot & 2,04 & 1,00 & 5,33 & 4,12 \\
\hline $\begin{array}{l}\text { Promedio de bytes sumados por } \\
\text { editor (general) }\end{array}$ & 108,56 & 144,08 & 726,26 & $1.306,83$ \\
\hline $\begin{array}{l}\text { Promedio de bytes sumados por } \\
\text { edición (general) }\end{array}$ & 56,02 & 227,57 & 19,73 & 228,27 \\
\hline
\end{tabular}




\begin{tabular}{|c|c|c|c|c|}
\hline \multicolumn{5}{|l|}{ Usuarios más activos } \\
\hline $\begin{array}{l}\text { Porcentaje de ediciones hechas por } \\
\text { los } 10 \text { usuarios activos sobre el total } \\
\text { de ediciones }\end{array}$ & $20,46 \%$ & $35,98 \%$ & $25,05 \%$ & $29,35 \%$ \\
\hline $\begin{array}{l}\text { Porcentaje de vigilantes sobre } \\
\text { editores (general) }\end{array}$ & $3,76 \%$ & $1,16 \%$ & $6,62 \%$ & $1,09 \%$ \\
\hline $\begin{array}{l}\text { Protección contra editores novatos } \\
\text { o IPs }\end{array}$ & no & no & no & No \\
\hline \multicolumn{5}{|l|}{ Visitas a las páginas } \\
\hline
\end{tabular}

Al analizar una voz de Wikipedia es importante entender cuál ha sido el sistema de construcción. La voz "idioma español" ha sido redactada por 3.612 usuarios a lo largo de 17 años. De estos, 1.156 han sido editores con nombre, mientras que 2.357 fueron usuarios anónimos o sin identificar (IPs). Se trata, como se observa, de un volumen de actividad inmenso. La voz ha sido mejorada también de manera automática por 99 bots, que han corregido cuestiones menores (erratas o formatos).

Encontramos que cada editor que ha trabajado en el artículo ha realizado 3,44 ediciones de promedio, de modo que suma una media de aportaciones equivalente a 726,26 bytes. Estos datos son estadísticos y no reflejan con claridad la pluralidad de la voz, pues se trata de medias aritméticas. Para medir el impacto de la construcción de una voz lo recomendable es estudiar el peso de los diez editores que más han contribuido a dicha entrada. En este caso, la participación de los usuarios más activos solo representa el 25,05\% del total del artículo; se trata, por tanto, de una voz construida de forma plural y sin un control monopolístico. Los datos de la "controversia" son también elevados aunque no llegan a las altas cifras de la voz del idioma.

Un dato realmente importante es que las discusiones de ambas voces son significativamente grandes por su tamaño (medido en bytes), la participación de las diversas instancias enunciativas; incluso hay más secciones en las discusiones que en las propias voces. Esto parece confirmar que el debate entorno a la lengua española es uno de los temas más importantes en la Wikipedia de los hispanohablantes.

El análisis cuantitativo nos ha permitido, por tanto, corroborar las hipótesis de partida. El volumen de actividad en torno a la construcción de las voces seleccionadas permite dar cuenta de la forma de trabajo colaborativo de la enciclopedia. 
El análisis cuantitativo del tamaño de las voces analizadas, los índices de la "pretendida calidad" (elevado número de referencias en el texto, pero, sobre todo, la calidad de las referencias) y el volumen de usuarios implicados son aspectos que nos han permitido ilustrar no solo el proceso colaborativo de construcción de la enciclopedia, sino su forma de proceder ante el planteamiento de la complejidad y la pluralidad del idioma español.

\subsection{Resultados y análisis: (des)cortesía}

Como hemos podido comprobar a partir del análisis cuantitativo descrito en los apartados anteriores, las discusiones forman parte consustancial de la dinámica impuesta por Wikipedia para la construcción del conocimiento colaborativo, con la finalidad de mejora constante de la enciclopedia.

Al margen de la preocupación de Wikipedia por la utilización de fuentes de referencia y otros aspectos que redunden en su calidad, existe una preocupación paralela por su buen funcionamiento.

Como apuntábamos en el apartado 2.2., las discusiones en torno a las voces seleccionadas se aproximan a determinados foros de opinión, puesto que tienen un propósito-tema en torno al que se genera el debate, y, como en aquellos, la propia estructura endógena de Wikipedia se afana, cada vez más, por articular determinados mecanismos para asegurar el orden en la gestión de contenidos y formas de expresión. De forma constante, en la página se reitera que ha de prevalecer un comportamiento cívico -también lo recuerdan algunos usuarios- a la hora de sugerir/aconsejar que se realicen cambios en los artículos, comunicar errores a otros usuarios, completar información... Directrices que no siempre se siguen por lo que junto a intervenciones de usuarios en las que prevalece el acuerdo, que se expresa de forma directa o indirecta, también se registran aquellas en las que se muestra el desacuerdo, total o parcial, manifestado de forma descortés o no.

Como señala Brenes Peña (2011: 11), la cultura actual es proclive a la crítica, y "el desacuerdo, la confrontación y la disputa se han ido convirtiendo, por diversos motivos, en formas de interacción bastante frecuentes". Pero si bien el desacuerdo se puede manifestar de forma cortés, mucho más frecuente es que se formule descortésmente.

Lo que vamos a analizar en el apartado 4.2.1. es la naturaleza de estas discusiones. Centraremos nuestro interés en ilustrar algunas de las estrategias de (des)cortesía empleadas.

\subsubsection{Afiliación y acuerdo}

La manifestación exclusiva de acuerdo no suele ser la fórmula mayoritaria en las discusiones, aunque la propia dinámica de la enciclopedia no solo propicia las intervenciones que permitan corregir, es decir, rechazar una información, sino también ratificarla, posicionarse a favor de uno u otro usuario. Cuando aparece el acuerdo, puede hacerse explícito de una manera directa mediante el empleo del propio verbo realizativo (coincido, estoy de acuerdo).

(3) Coincido totalmente con el comentario de Cipión, yo vivo en Cataluña y detecto un uso creciente del fenómeno que él reporta. Es una buena observación, tal vez deberíamos buscar una cita de un medio que recogiera ese hecho de dar referencias del fenómeno Davius. 10:55 3 mar 2007 (CET) (Discusión: Controversia por el nombre del idioma español, 2020).

Es más, como se trata de controversias, cuando lo único que se busca es la afiliación, es frecuente que, como en el ejemplo (3), aparezca intensificado, como forma de acuerdo total, mediante el adverbio totalmente. En este ejemplo, el movimien- 
to de acuerdo se refuerza, a su vez, con el acto expresivo valorativo cumplido (es una buena observación), cuya función primaria es más afectiva y social que referencial. Es un acto más integrador que distanciador (Jaworski, 1995: 63), que permite crear un ambiente de amabilidad en tanto que estrategia de afiliación de la imagen del destinatario, así como de la del emisor.

El acuerdo puede manifestarse también de forma indirecta como (4). El usuario añade información para corroborar la opinión de otro usuario y posicionarse en su línea argumentativa:

(4) Diccionario Panhispánico de Dudas 2005

Creo que esto resuelve las controversia:

Español. Para designar la lengua común de España y muchas naciones de América, y que también se habla como propia en otras partes del mundo, son válidos los términos [...] (Discusión: Controversia por el nombre del idioma español, 2020).

Dado que entran en juego determinadas variables como el objetivo de la discusión y la necesidad que tiene el usuario de mostrarse en sus aportaciones como un buen conocedor de aquello sobre lo que opina, las justificaciones son constantes; en ellas aparecen ejemplificaciones, citas, argumentos de autoridad, analogías... En la opinión en la que se manifiesta el acuerdo es habitual que exista un movimiento de justificación mediante el que el usuario intenta demostrar el criterio suficiente tanto para valorar positivamente como para juzgar y criticar (en el caso de los actos disentivos). En este sentido, el usuario estaría reforzando su propia imagen-actividad de autoimagen (Hernández Flores, 2013)- como persona con la capacidad y fiabilidad para realizar aportaciones relevantes.

Como en el ejemplo (3), la justificación puede llevarse a cabo mediante la manifestación en primera persona (yo vivo) de una experiencia propia, que intenta que le otorgue cierto criterio como opinante. Si bien Wikipedia recrimina el uso de valoraciones, en este caso se pretende que actúe más bien como argumento de autoridad que como opinión exclusivamente personal. Se presupone que cualquier vivencia otorga mayor credibilidad a la argumentación de quien la ha experimentado. En (4), la inclusión de la cita textual de la entrada "español" también se convierte en argumento de autoridad en tanto que el Diccionario Panhispánico de Dudas es uno de los diccionarios de la institución de referencia sobre la lengua española, la RAE.

\subsubsection{Discrepancia y (des) cortesía}

Frente a la manifestación de acuerdo, la de desacuerdo con la opinión emitida por otro usuario en la discusión es incluso más habitual. Estamos ante actos disentivos, es decir, aquellos que "niegan la veracidad o validez del contenido proposicional afirmado por otro interlocutor o, dicho de otra forma, se centran en la impugnación de la información que ha sido o está siendo emitida por el otro participante en la comunicación" (Brenes Peña, 2011:32)2.

2 Mediante la contestación o desacuerdo (fórmulas negativas, fórmulas metacomunicativas en primera persona, interrogaciones exploratorias o hipotéticas); objeción u oposición (marcadores discursivos contraargumentativos, interrogaciones con fines argumentativos); concesión (aceptación más oposición, conectores concesivos de distanciamiento; corrección; justificación (Brenes Peña, 2011: 56). 
(5) Se conoce y usa más como español

No estoy de acuerdo en renombrar la página como castellano porque no es la palabra de mayor uso, pero no tiene nada de denigrante la palabra sobre todo cuando muchos países dicen castellano sin ningún problema [...]

JaimeDes (discusión) 15:27 4 ene 2016 (UCT) (Discusión: idioma español, 2020).

Como en (5), el desacuerdo puede manifestarse mediante la forma metacomunicativa en primera persona (no estoy de acuerdo), en la que aparecen la negación y el verbo realizativo, u otras fórmulas como el verbo de creencia (no creo), el verbo discrepar (discrepo), valorando negativamente la opinión del otro (tu opinión no me convence) o simplemente con la negación (no).

La discrepancia puede realizarse sin descortesía, lo que precisamente intenta potenciar la propia enciclopedia. De hecho, en opiniones como la del ejemplo (5), el opinante manifiesta su desacuerdo, normalmente de forma atenuada como mecanismo de protección de su imagen (como persona ecuánime, tolerante, ponderada en sus opiniones) y de cortesía hacia el otro usuario (respetuosa con otras intervenciones). Por ello, como estrategia de atenuación, justifica su decisión señalando "no es la palabra de mayor uso" (el castellano), pero realiza una concesión atenuante introducida por pero, "pero no tiene nada de denigrante la palabra sobre todo cuando muchos países dicen castellano sin ningún problema".

Como estrategias de afiliación, tanto en las intervenciones en las que se manifiesta acuerdo como desacuerdo, a veces se recurre a fórmulas de apertura y cierre conversacionales como saludos. A pesar de su naturaleza asíncrona, las discusiones actúan como foros en los que alternan turnos de habla. Por ello, la intervención de cada usuario se inicia o finaliza con este tipo de actos de habla. También se registran otros actos expresivos como agradecimientos. Todos ellos son actos de convivencia social, cuyo objetivo es el establecimiento y mantenimiento de una atmósfera cortés (Leech, 1983: 104). En concreto, el agradecimiento es un acto reactivo que lleva a cabo el hablante basándose en una acción previa realizada por el oyente (Searle, 1969: 67) y tiene una importante función social (Norrick, 1978: 285; Eisenstein y Bochman, 1996: 64). Permite establecer cordialidad, contribuir al desarrollo armonioso de las relaciones sociales entre los miembros de una comunidad, reestablecer el equilibrio de la relación coste-beneficio entre hablante y oyente, o reforzar la imagen positiva del hablante (Haverkate, 1994: 82, 93). Por ello, la recurrencia de este acto de habla, que es uno de los más formularios, está muy acorde con la política de la enciclopedia, que, cada vez en mayor medida, pretende instaurar la cordialidad entre los usuarios ante el tono enconado que han adquirido algunas controversias.

(6) No sin referencias. Gracias por tu mensaje, pero para que podamos incluir la información que nos proporcionas, es necesario que aportes aquí referencias fiables que la respalden, como pueden ser libros, páginas web, periódicos, revistas, etc. Puedes consultar Wikipedia:Verificabilidad para más información al respecto. Geom (discusión) 00:27 15 nov 2019 (UTC) (Discusión: idioma español, 2020).

Por otra parte, la discrepancia se realiza en no pocos casos -más de los deseados, puesto que la enciclopedia insiste, cada vez más, en la necesidad de mantener las formas- mostrando no solo desacuerdo, sino formulando este de una forma 
abiertamente descortés. En este sentido, se registran las mismas fórmulas de descortesía que en otras interacciones ${ }^{3}$. Por ejemplo, descalificaciones de las palabras del otro (es absurdo, falso, una tontería...).

(7) Hola, leí en este artículo que en partes de México se utiliza el voseo, eso es una gran mentira [...] jmko (discussion) 08:02 07 mar 2009 (UTC) (Discusión: idioma español, 2020).

(8) Para no alargar la lista que se pasó de ridícula [...] EEIM (discusión) 05:44 15 jul 2019 (UTC) (Discusión: idioma español, 2020).

Cuando el tono de la intervención del usuario es deliberadamente descortés o simplemente no muestra una preocupación por las formas de cortesía, se recurre a procedimientos de intensificación. En el ejemplo (7) habría sido suficiente el sustantivo mentira para descalificar las palabras del otro usuario, pero este, a su vez, se enfatiza mediante el adjetivo gran$d e$. Intensificación que, en ocasiones, se realiza a partir de recursos ortotipográficos como versalitas o mayúsculas (Eso es FALSO, completamente). En este caso, estaríamos ante la transcripción de un recurso prosódico como el acento enfático o de insistencia. En cierta medida, estas discusiones se aproximan a los foros de opinión de las redes sociales, en los que es frecuente cierta hibricidad, entendida esta característica como la combinación de rasgos propios de lo oral, pero en textos escritos (Maíz-Arévalo y García-Gómez, 2013). Estaríamos ante un discurso interactivo escrito (Ferrara, Brunner, and Whittemore, 1991: 8). Precisamente, como en las redes sociales (Twitter, Facebook...), no se trata de intercambios dialógicos, de un diálogo síncrono entre los participantes, sino de un discurso colectivo configurado por la suma de voces que se pronuncian en torno a un tema (Mancera Rueda y Pano Alamán, 2013).

Como podemos comprobar a través de los ejemplos, se suelen poner en evidencia las palabras del otro, bien acusándolo de mentir o "atacando su imagen, relativizando o negando el valor de las pruebas aportadas" (Fuentes Rodríguez y Alcaide Lara, 2008: 24). Se recurre para ello también a ironías (9), símiles (9) o metáforas:

(9) Carencias en el articulón

- Muy extenso, parece un boletín o una monografía (sin firma) (Discusión: idioma español, 2020).

No suele ser habitual el insulto directo, que es una estrategia convencional de descortesía (Culpeper, 2011: 135). Pero, en su lugar, se descalifica mediante la referencia al usuario bajo la forma de tercera persona, "despojándole de la categoría de persona del discurso, para pasar a ser la "cosa" de la que se habla” (Fuentes Rodríguez y Alcaide Lara, 2008: 24):

(10) Sinceramente no veo adecuado que wikipedistas nada objetivos con todo lo relacionado con lo español sean los que impongan los mapas que ellos deciden en cada momento. En el mapa del Idioma Español faltan referencias obligatorias [...]. Adeuagur (discusión) 03:04 31 jul 2011 (UTC) (Discusión: idioma español, 2020).

Como sucede en las redes sociales, en ocasiones se ataca más la identidad grupal (las coaliciones que se establecen entre usuarios) que la individual (García-Conejos Blitvich y Bou-Franch, 2019: 99).

Finalmente referimos los casos en los que la descortesía queda patente por "el simple deseo de boicotear la intervención del contrario ('no reclama turno, pero interviene'), y demostrar la disconformidad con lo que se está diciendo") (Fuentes

3 Véanse las taxonomías sobre estrategias de descortesía propuestas por Culpeper (2005), Fuentes Rodríguez y Alcaide Lara (2008) o Lorenzo-Dus, Garcés-Conejos Blitvich y Bou-Franch (2011). 
Rodríguez y Alcaide Lara, 2008: 22). Como podemos comprobar en la conversación del ejemplo (11), los usuarios/editores de contenidos de Wikipedia recriminan este comportamiento:

(11) Hola. El usuario Gonce insiste en poner [...] Sin duda, el yeísmo rioplatense es muy interesante, pero no es el sitio para mencionarlo, esamos hablando de yeísmo en 3 líneas y no corresponde enumerar cada una de sus realizaciónes. Yo no sigo revirtiendo porque se ve que no va a detenerse sin participación de otros. Gracias. Lin linao ¿dime? 00:19 11 jun 2009 (UTC)

(. ) el usuario lin lanao insiste en eliminar mi aporte de yeísmo rioplatense, es relevante, esta solo es una aclaración menor y este usuario no desiste en eliminarla. Juzguen ustedes su accionar y aporten a la causa por favor. Gonce (discusión) 00:30 11 jun 2009 (UTC) Gonce

Por favor, cesá en tu actitud o podría ser considerada sabotaje. Wikipedia no es el lugar para imponer tus preferencias personales o tu creencia, como decís en su discusión a Lin linao [...] Gracias por tu comprensión. -galio... ? 20:14 11 jun 2009 (UTC) (Discusión: idioma español, 2020).

\section{Conclusiones}

En este artículo hemos mostrado un estudio de caso para ejemplificar el funcionamiento interno de Wikipedia, una enciclopedia online en constante evolución, fruto de la construcción colaborativa entre usuarios. En concreto, para ilustrar la actividad de Wikipedia en español, hemos revisado, mediante un análisis cuantitativo, el comportamiento y el proceso de construcción de dos voces representativas en esta versión de la enciclopedia.

Se observa que las voces "idioma español" y "controversia por el nombre del idioma español" presentan en Wikipedia una fuerte y compleja discusión que refleja la problemática suscitada en torno a la lengua y sus variedades. Por ello, parece confirmarse la hipótesis 1 (H1): existe un importante número de editores (anónimos o identificados) que han contribuido de una forma plural a la creación de las voces. En especial resulta relevante el gran número de vigilantes que presenta cada artículo estudiado pues indica el interés y la preocupación que la comunidad muestra sobre el idioma español.

Por lo que respecta a la hipótesis 2 (H2), las discusiones de ambas voces se presentan como foros de debate amplios y plurales, que comparten características con los foros de opinión especializados, articulados en torno a un tema, y que cuentan con un gestor de contenidos y formas de expresión; pero que, a pesar de los esfuerzos de Wikipedia por evitarlo, también se aproximan a otros foros en los que se vuelcan opiniones personales. En cualquier caso, las estrategias de (des) cortesía empleadas nos permiten apreciar el tono de esas discusiones, y cómo se lleva a cabo la búsqueda del consenso para contribuir a la construcción del conocimiento colaborativo, que es la esencia de Wikipedia.

Precisamente, el comportamiento de construcción de la Wikipedia en español se enmarca dentro del consenso, que puede incluir la discusión, el debate y hasta la controversia. Muy significativo es que la Wikipedia en español no se realiza de forma mayoritaria desde ningún estado o ninguna comunidad, sino que tiene una fuerte presencia internacional. Del mismo modo, no existe un discurso monopolístico sino plural; los diez editores que más han contribuido a la construcción de estas voces representan solo una pequeña parte del total. Por ello, parece confirmarse la hipótesis 3 (H3), es decir, se puede entender que se trata de entradas sin un dominio monopolístico ni una autoridad central que articulen su construcción. 


\section{Referencias bibliográficas}

Alexa (2020). Alexa rank. Recuperado en: https://www.alexa.com/siteinfo/wikipedia.org

Anexo:Wikipedias. (2020). Wikipedia, la enciclopedia libre. Recuperado en: https://es.wikipedia.org/wiki/ Anexo:Wikipedias

BBC news. (2019, 14 Mayo). Wikipedia blocked in China in all languages. BBC News Services. Recuperado en: https://www. bbc.com/news/technology-48269608

Brenes Peña, E. (2011). Actos de habla disentivos. Indentificación y análisis. Sevilla: Alfar.

Cassany, D. (2012). En_línea. Leer y escribir en la red. Barcelona: Anagrama.

Claes, F., y Deltell, L. (2019). Wikipedia en español. Comportamiento de la comunidad hispanohablante en el trabajo colaborativo en internet. Estudios sobre el Mensaje Periodístico, 25(3), 1357-1378. doi: 10.5209/esmp.66992

Claes, F. y Deltell, L. (2020). Wikipedia y universidades: trabajo colaborativo en torno

a universidades iberoamericanas. Revista de Educación, 389, 243-266. doi: 10.4438/1988-592X-RE-2020-389-461

Collier, B. y Bear, J. (2012). Conflict, confidence, or criticism: an empirical examination of the gender gap in Wikipedia. CSCW'12, Seatle, Washington, 383-392.

Culpeper, J. (2011). Impoliteness. Using Language to Cause Offence. Cambridge: Cambridge University Press.

Discusión: idioma español (2020). Wikipedia, la enciclopedia libre. Recuperado en: https://es.wikipedia.org/wiki/ Discusión:Idioma_español

Discusión: controversia por el nombre del idioma español (2020). Wikipedia, la enciclopedia libre. Recuperado en: https:// es.wikipedia.org/wiki/Discusi\%C3\%B3n:Controversia_por_el_nombre_del_idioma_espa\%C3\%B1ol

Eisenstein, M. y Bodman, J. (1993). Expressing Gratitude in American English. En Kasper, G.

Blum-Kulka, S. (edd.), Interlanguage Pragmatics, New York/Oxford: Oxford University Press, 64-81.

Eligio Mendoza, I. M. y otros (2016). El desarrollo del pensamiento crítico mediante el debate asincrónico en foros virtuales de educación secundaria. Revisa Aletheia, 8 (1), 100-115.

Ferrara, K., Brunner, H, y Whittermore, G. (1991). Interactive Written Discourse as Emergent Register. Written Communication, 8 (1), 8-34.

Fuentes Rodríguez, C. y Alcaide Lara, E. (2008). Descortesía, agresividad y violencia verbal en la sociedad actual. Sevilla: Universidad Internacional de Andalucía.

Fundación Princesa de Asturias (2015). Wikipedia premio de cooperación internacional 2015. Recuperado en: https:// www.fpa.es/es/premios-princesa-de-asturias/premiados/2015-wikipedia.html?especifica $=0$

Garcés-Conejos Blitvich, P. y Bou-Franch, P. (2019). La descortesía en las redes sociales. En Placencia, M. E. y Padilla, X. (edd.), Guía práctica de pragmática del español actual, London: Routledge.

Giles, J. (2005). Internet encyclopaedias go head to head. Nature, 438(7070), 900-901. doi:10.1038/438900A 
Haverkate, H. (1994). La cortesía verbal. Estudio pragmalingüístico. Madrid: Gredos.

Hernández Flores, N. (2013). Actividad de imagen: caracterización y tipología en la interacción comunicativa. Pragmática Sociocultural, 1 (2), 175-189.

Hube, C. (2017). Bias in wikipedia. En International World Wide Web Conferences Steering Committee 717-721. doi: $10.1145 / 3041021.3053375$

Jaworski, A. (1995). This is not an empty compliment! Polish compliments and the expression of solidarity. International Journal of Applied Linguistics, 5 (1), 63-94.

Instituto Cervantes. (2019). El español: Una lengua viva. Informe 2019. Madrid: Instituto Cervantes.

Kubátová, J. (2012). Growth of collective intelligence by linking knowledge workers through social media. LESIJ-Lex ET Scientia International Journal, 19(1), 135-145.

Lerner, J. y Lomi, A. (2020). The free enciclopedia that anyone can dispute: An analysis of the microstructural dynamics of positive and negative relations in the production of contentious Wikipedia articles. Social Network, 60, 11-25. doi: 10.1016/j.socnet.2018.12.003

List of Wikipedias by speakers per article. (2018, Junio 23). Wikimedia Meta-wiki. Recuperado en: https://w.wiki/X6k Lorente, P. (2020). El conocimiento hereje. Buenos Aires: Editorial Paidós.

Lorenzo-Dus, N., Garcés-Conejos Blitvich, P. y Bou-Franch, P. (2011). Online polylogues and impoliteness: The case of posting sent in response to the Obama Reggaeton YouTube video. Journal of Pragmatics. 43, 2578-2593.

Los cinco pilares de Wikipedia (2020). Wikipedia, la enciclopedia libre. Recuperado en: https://es.wikipedia.org/wiki/ Wikipedia:Los_cinco_pilares

Maíz-Arévalo, C. y García-Gómez, A. (2013). You Look Terrific! Social Evaluation and Relationships in Online Compliments. Discourse Studies, 15 (6), 735-760.

Mancera Rueda, A. y Pano Alamán, A. (2013). Nuevas dinámicas discursivas en la comunicación política en Twitter. Círculo de Lingüística Aplicada a la Comunicación, 56, 53-80

Mayer-Schönberger, V. y Cukier, K. (2013). Big data: la revolución de los datos masivos. Madrid: Turner.

Norrick, N. (1978). Expressive Illocutionary Acts. Journal of Pragmatics, 2 (3), 277-291.

Páginas de discusión (2020). Wikipedia, la enciclopedia libre. Recuperado en: https://w.wiki/X6n

Pano Alamán, A. (2008). Estrategias comunicativas y lingüísticas en listas y foros de debate en internet. Círculo de Lingüística Aplicada a la Comunicación, 33, 28-44.

Páginas de discusión (2020). Wikipedia, la enciclopedia libre. Recuperado en: https://es.wikipedia.org/wiki/ Wikipedia:Páginas_de_discusión

Rodríguez-Mateos, D. y Hernández-Pérez, T. (2018). Los periódicos españoles como fuente de referencia en Wikipedia. El Profesional de la Información, 27 (6), 1323-1333. https://doi.org/10.3145/epi.2018.nov.15 
Searle, J. (1969). Speech Acts. An Essay in the Philosophy of Language, Cambridge: Cambridge University Press.

Timothy. (2005, 18 de abril). The early history of nupedia and wikipedia: A memoir. Recuperado en: https://features. slashdot.org/story/05/04/18/164213/the-early-history-of-nupedia-and-wikipedia-a-memoir

Tkacz, N. (2011, 20 de enero). The Spanish fork: Wikipedia's ad-fuelled mutiny. Wired.Co.Uk Recuperado en: https:/ /www. wired.co.uk/article/wikipedia-spanish-fork

Tramullas, J. (2015). Wikipedia como objeto de investigación. Anuario ThinkEPI, 9, 223-226. doi:10.3145/thinkepi.2015.50 Vigara Tauste, A. M. ${ }^{a}$ y Hernández Toribio, M. ${ }^{\text {a }}$. (2011). Ciber(des)cortesía en los foros de opinión de la prensaescrita: un ejemplo. ELUA, 25, 353-379. doi: 10.14198/ELUA2011.25.12

Wedemeyer, B., Yakubova, N., Kallenbach, J., Ekdahl, A., Lesko, L., Reed, E., \& Schwartz, K. (2008). Quality of the science articles on the english wikipedia: Preliminary results. En Wikimania 2008.

Wikimedia Foundation (2020). Nuestro trabajo. Recuperado en: https://wikimediafoundation.org/es/our-work/

Wikipedia: Autoconfirmados (2020). Wikipedia, la enciclopedia libre. Recuperado en: https://es.wikipedia.org/wiki/ Wikipedia:Autoconfirmados

Wikipedia: Páginas de discusión (2020) Wikipedia, la enciclopedia libre. Recuperado en: https://es.wikipedia.org/wiki/ Wikipedia:P\%C3\%Alginas_de_discusi\%C3\%B3n

Wikipedia: Punto de vista neutral (2020) Wikipedia, la enciclopedia libre. Recuperado en: https://es.wikipedia.org/wiki/ Wikipedia:Punto_de_vista_neutral

Wikistats (2013). Wikimedia Traffic Analysis Report. Recuperado en: https://w.wiki/X6m

Wikistats. (2020). Wikimedia statistics. Recuperado en: https://w.wiki/Qu8

\section{Investigación financiada:}

Este trabajo recibe el apoyo del Proyecto 94, Inovación Docente 2020-21. Universidad Complutense de Madrid. 